\title{
O ensino de história medieval como tema de reflexão em disciplina obrigatória do curso de graduação em História: relato de uma experiência
}

The teaching of medieval history as a subject of reflection in a compulsory subject of History

graduation course: report of an experience

Andréia Cristina Lopes Frazão da Silva*

\section{Resumo}

$\mathrm{O}$ artigo descreve a experiência de introduzir uma unidade sobre ensino de história medieval na disciplina de História Medieval II, oferecida no curso noturno da Graduação em História da UFRJ. No texto, além de apresentar as atividades desenvolvidas na referida unidade, é feita uma avaliação do impacto para os alunos do tratamento desse tema, a partir da análise de um questionário que foi respondido pelos discentes ao final do semestre letivo. $\mathrm{O}$ objetivo principal de relatar essa experiência é estimular outros professores a buscarem formas de aproximar a prática docente em diferentes níveis escolares à reflexão acadêmica.

Palavras-chave: História Medieval; ensino; pesquisa.
Abstract

This article describes the experience of introducing a unit about the teaching of medieval history in the discipline Medieval History II, offered in the night turn of the Graduation in History of UFRJ. In this text, in addition to presenting the activities developed in that unit, an assessment of the impact of the treatment of this theme on the students is made, based on the analysis of a questionnaire that was answered by them at the end of the semester. The purpose of reporting this experience is to encourage other teachers to seek out ways to bring the practice of teaching in different school levels to academic reflection. Keywords: Medieval History; teaching; research.

O objetivo deste artigo é partilhar uma experiência realizada no primeiro semestre de 2011, quando incluí uma unidade sobre ensino de história medieval na disciplina História Medieval II, oferecida por mim no turno noturno do Curso de Graduação em História da UFRJ. ${ }^{2}$

\footnotetext{
* Universidade Federal do Rio de Janeiro (UFRJ). andreiafrazao@terra.com.br
} 
Estão previstas no currículo do Curso de Graduação em História da UFRJ duas disciplinas obrigatórias referentes ao medievo, as chamadas História Medieval I e II. Em História Medieval I, o foco é o período tradicionalmente denominado como Alta Idade Média, séculos $\mathrm{V}$ ao $\mathrm{X}$, abarcando reflexões sobre as sociedades da Europa Ocidental, do Islã e do Mundo Bizantino. Em História Medieval II são abordados diversos aspectos da história da Europa Ocidental e das relações estabelecidas com o Oriente nos séculos XI ao XV. Ou seja, trata do período que se convencionou chamar de Baixa Idade Média. ${ }^{3}$

A disciplina História Medieval II, como outras obrigatórias oferecidas no curso de Graduação em História da UFRJ, tem carga horária total de 60 horas/ aula, divididas em 15 encontros no decorrer do semestre, com 4 horas/aula cada. No turno noturno, o horário das aulas é de $18 \mathrm{~h}$ às $21 \mathrm{~h} 40$, com um intervalo de 20 minutos. No primeiro semestre de 2011, a disciplina foi oferecida às terças-feiras. Cursaram a disciplina 41 alunos, dos 54 que se inscreveram originariamente.

Ainda que a distribuição curricular aprovada pelo Conselho de Ensino de Graduação (CEG) da UFRJ sugira que o aluno do turno noturno curse a disciplina História Medieval II no quarto período do bacharelado, após ter cursado a História Medieval I, poucos seguem a proposta. Como Metodologia da História I, cursada geralmente no primeiro semestre, é o único pré-requisito para as disciplinas História Medieval I e II, alguns alunos cursam simultaneamente ambas, já no terceiro período, ou, por não terem interesse particular no tema ou devido a problemas diversos, deixam para cursá-la no final do bacharelado. Nesse sentido, dentro do grupo que cursou a disciplina História Medieval II sob minha responsabilidade no primeiro semestre de 2011, havia alunos do terceiro até o décimo período. ${ }^{4}$

O grupo de alunos era extremamente heterogêneo: alguns estavam cursando as disciplinas da licenciatura e outros já estavam inseridos no mercado de trabalho, atuando como professores. Nem todos os alunos eram do turno noturno; alguns alunos do integral, por motivações diversas, optaram por cursar a disciplina oferecida nesse horário. ${ }^{5}$ Além disso, havia pessoas que já estavam cursando sua segunda graduação.

Participando das atividades relacionadas à disciplina, encontravam-se dois monitores - um voluntário e um bolsista - e um mestrando do Programa de Pós-graduação em História Comparada da UFRJ, cumprindo o estágio docência. 
Esses alunos tiveram um papel fundamental no desenrolar da disciplina, realizando diversas tarefas. Por exemplo, auxiliaram os alunos em diferentes questões, como ajuda na organização de grupos de trabalho, recordar a data de entrega de trabalhos, responder a dúvidas sobre as leituras base do curso etc. Eles também cuidaram dos materiais didáticos - textos a serem distribuídos, mapas - e equipamentos - como datashow e vídeos, usados em aula. Além disso, as monitoras apresentaram e discutiram com a turma alguns dos textos base do curso e o mestrando ministrou algumas aulas, preparadas sob minha supervisão, como previsto no estágio.

O conteúdo programático do curso foi dividido em 11 unidades, que tiveram como temas centrais estes tópicos:

1. os saberes sobre o medievo: medievalismo e medievalidade; ${ }^{6}$

2. principais visões historiográficas sobre o Medievo;

3. o medievalismo no Brasil;

4. o ensino de história medieval no Brasil;

5. aspectos demográficos do Ocidente medieval nos séculos XI ao XV;

6. aspectos econômicos do Ocidente medieval nos séculos XI ao XV;

7. aspectos políticos do Ocidente medieval nos séculos XI ao XV;

8. aspectos religiosos do Ocidente medieval nos séculos XI ao XV;

9. aspectos sociais do Ocidente medieval nos séculos XI ao XV;

10. aspectos educacionais e artísticos do Ocidente medieval nos séculos $\mathrm{XI}$ ao XV; e

11. a História das relações entre a Europa Ocidental e o Império Bizantino e o Islão (séculos XI ao XV).

Segundo o Manual do Aluno do Instituto de História da UFRJ, as disciplinas obrigatórias

têm um duplo objetivo: um diálogo com outras Ciências Humanas e um tratamento horizontal das tradicionais áreas de conhecimento histórico a partir de um recorte temático temporal, visando possibilitar ao graduando um conheci- 
mento mínimo indispensável em História: Antiga, Medieval, Moderna, Contemporânea, Brasil e América. (Bustamante, 2011, p.6)

Em harmonia com o que propõe o documento citado, a escolha das temáticas abordadas no decorrer da disciplina teve, portanto, como principal meta introduzir o aluno no conhecimento histórico sobre as sociedades medievais nos séculos XI ao XV. Para tanto, privilegiamos, sobretudo, a discussão historiográfica; a reflexão interdisciplinar; o diálogo entre a visão acadêmica e a do senso comum sobre o período e, o que privilegiamos para discutir neste artigo, a análise do saber escolar ${ }^{7}$ sobre o medievo.

Partindo dessas diretrizes, foram traçados como principais objetivos da disciplina que, ao final do semestre, os alunos deveriam ser capazes de: diferenciar medievalismo e medievalidade; conhecer as principais correntes historiográficas aplicadas ao estudo do medievo no Brasil; identificar as principais tendências da pesquisa acerca da história medieval no Brasil; debater o ensino de história medieval nos níveis fundamental e médio no Brasil; analisar criticamente textos historiográficos e textos didáticos e paradidáticos; elaborar comentários históricos de documentos medievais impressos; fundamentados na historiografia, discutir as principais transformações processadas na Europa Ocidental e nas relações entre as sociedades estabelecidas nesse espaço e o Império Bizantino e o Islão do século XI ao XV.

Leciono disciplinas obrigatórias de história medieval desde que ingressei no magistério superior, em 1988. Durante todos esses anos, eventualmente incluía como uma das atividades do curso alguma reflexão sobre livro didático. Nos últimos anos, ${ }^{8}$ contudo, dediquei ao tema uma unidade. Optei por incluir essa temática por alguns motivos, que passo a apresentar.

Ainda que na UFRJ o aluno possa cursar somente o bacharelado, todos os que optam pela licenciatura cursam todas as disciplinas oferecidas no bacharelado. Logo, o Curso de Graduação em História visa, ainda que não de forma exclusiva, a formação de professores.

Há que despertar nos alunos o interesse por articular ensino e pesquisa, pois são atividades complementares, não excludentes. Além disso, não podemos perder de vista que o ensino de história é um tema acadêmico sobre o qual têm sido desenvolvidas diversas pesquisas, inclusive na própria UFRJ, e que são do desconhecimento de muitos de nossos alunos. 
Para além das articulações entre ensino e pesquisa, é fundamental que os discentes percebam que o ensino é, também, um tema político fundamental, já que se relaciona às políticas públicas para educação implantadas no Brasil, à questão dos salários docentes; à qualificação profissional, ao acesso à escola, à relação entre sociedade e universidade etc.

Por fim, há que sublinhar que o espaço da universidade é o local privilegiado para o diálogo não só entre alunos em diferentes níveis de formação e com metas profissionais diversas, mas também para as reflexões interdisciplinares e o diálogo com a sociedade. Ou seja, discutir sobre o ensino de História não deve ser tarefa só para pedagogos.

No que concerne de forma específica ao estudo do medievo, defendo que esta seja uma preocupação a ser levada a sério pelos medievalistas brasileiros que atuam no ensino superior, formam os futuros profissionais de ensino e realizam pesquisas. E não só porque temos algo a oferecer, mas, sobretudo, porque também temos muito a aprender, sobretudo sobre as diversas implicações dos processos de ensino-aprendizagem e sobre as formas como o conhecimento circula nos variados setores da sociedade. Não é inútil relembrar, aqui, que para algumas parcelas da população brasileira o período medieval ainda é a "Idade das Trevas" ou é compreendido pela perspectiva romântica e idealizadora. Em contrapartida, outros setores sequer possuem uma referência sobre o período e desconhecem o patrimônio cultural medieval.

Por consideramos, portanto, que é fundamental que o graduando reflita sobre o ensino da História, em especial a relacionada ao período medieval, na unidade quatro, o ensino de história medieval no Brasil, foram desenvolvidas três atividades distintas e complementares. Tais atividades foram realizadas tanto em sala de aula como extraclasse.

Como primeira atividade, foi sugerido aos alunos que lessem dois textos base. O primeiro, Idade Média, alteridade e ensino de História, de autoria de Nilton Mullet Pereira, professor da Faculdade de Educação da UFRGS, mestre e doutor em educação, que vem se dedicando à pesquisa das relações entre Ensino de História, Medievalismo e Etnocentrismo (Pereira, 2009, p.23-38). O segundo, de autoria de Marcelo Fernandes de Paula, mestrando que acompanhou o curso, escrito quando ainda cursava a Graduação: $A$ produção do conhecimento e seus locais de difusão: uma reflexão sobre o abismo (Paula, 2008, p.109-115). 
Os dois textos abordam diversas questões sobre o ensino de história medieval, tais como o uso do anacronismo no ensino da História Medieval, o preconceito ainda reinante no país sobre o medievo, o papel dos livros didáticos na reprodução de tais visões negativas ou esquemáticas sobre o período histórico em tela.

Ainda ligada à unidade, foi ministrada uma aula expositiva. Nela, os textos base foram comentados e alguns temas foram tratados com a turma. Os principais pontos discutidos foram:

- a complexa relação de ensino-aprendizagem, sob a qual incidem múltiplas variantes, tais como a formação do professor, o espaço escolar interno e externo; as políticas públicas; a motivação e o desejo pessoal dos envolvidos; os métodos e técnicas utilizados tanto pelo professor, ao ensinar, quanto pelo aluno, ao aprender.

- a longa tradição de ensino de história no Brasil, que a despeito das mudanças nas últimas décadas ainda se pauta, majoritariamente, na busca pelo nexo entre passado-presente-futuro, na perspectiva de que o processo histórico é evolutivo; na lógica da busca pela origem dos fenômenos; na generalização-esquematização; em juízos de valor etc.

- os conteúdos que são tradicionalmente ministrados sobre a história medieval nas escolas básica e média: "bárbaros", Império de Carlos Magno, Igreja, Feudalismo, a Sociedade das Três Ordens, Maomé, Bizâncio, e a crise do feudalismo.

- a apresentação e reflexão sobre os Parâmetros Curriculares Nacionais (PCNs) estabelecidos para o Ensino fundamental, em 1998, ${ }^{9}$ e as Orientações Curriculares Nacionais para o Ensino Médio (PCNEM), publicadas em 2006. ${ }^{10}$

- o papel do livro didático como instrumento fundamental no ensino-aprendizagem, pois é o principal recurso didático usado no ensino e até mesmo por muitos professores, para prepararem suas aulas.

- a apresentação do Programa Nacional do Livro Didático (PNLD), instituído em 1996 para o ensino fundamental, ${ }^{11}$ e o Programa Nacional do Livro Didático para o Ensino Médio (PNLEM), desde 2004. ${ }^{12}$

Como terceira atividade relacionada à unidade, foi solicitada a elaboração de um trabalho, a ser realizado em grupo, para entrega ao final do semestre: a 
análise de um livro didático com conteúdos de história medieval, utilizado no ensino fundamental ou médio. Foi entregue um roteiro, que deveria ser desenvolvido em etapas pelo grupo no decorrer do semestre. ${ }^{13} \mathrm{O}$ roteiro proposto foi apresentado, explicado e comentado em aula, item a item. O trabalho foi realizado extraclasse, mas em 2 horas/aulas, e foi dedicado um período para que os alunos, já organizados em grupos, trocassem ideias sobre o trabalho e tirassem dúvidas com os monitores, o mestrando e comigo sobre a tarefa proposta.

$\mathrm{O}$ roteiro, que segue ao final do artigo, está dividido em nove itens. $\mathrm{O}$ primeiro tinha como objetivo caracterizar a obra a ser analisada: título, editora, série a que se destina, ano de publicação, edição, informações sobre a coleção da qual faz parte, caracterização sobre o tipo de coleção - temática, integrada, intercalada ou convencional -, tal como prevê o Guia do PNLD. ${ }^{14}$

O segundo tem como meta identificar os autores quanto à formação, vinculação institucional e conjunto de obras produzidas, a fim de obter um perfil acadêmico dos escritores das obras em análise.

O terceiro item visa identificar informações quanto à forma do livro: tamanho das folhas, número de páginas, nitidez das letras impressas, disposição gráfica (descrição e avaliação), tipo de papel (espessura e cor), capa (qualidade e estética), encadernação, durabilidade, facilidade de manuseio e transporte, levando em conta a idade do grupo a que se destina, e preço. Tais aspectos, muitas vezes menosprezados na análise dos livros, são fundamentais, pois podem comprometer a saúde dos alunos em diversos aspectos, como pelo excesso de peso que precisam carregar todos os dias ou pela falta de nitidez das letras ou pela cor das páginas. Além disso, a obra pode dispersar o aluno, devido ao excesso de informações visuais, ou ainda dificultar a leitura em condições adversas, como, por exemplo, em ambientes com pouca luminosidade. E, por sua fragilidade, os livros podem facilmente soltar as folhas, manchar com água, rasgar a capa etc.

No quarto bloco estão os itens relacionados à análise do conteúdo: quais os temas abordados no livro; como é estruturado e organizado; que pressupostos pedagógicos fundamentam os conteúdos; que conceitos teóricos são empregados; que obras historiográficas e fontes são citadas; se o vocabulário e as informações que figuram na obra são adequados à idade/série a que se destina; qual a validade e profundidade das informações contidas no livro, se no 
material há preconceitos e juízos de valor. Neste item o grupo deveria, ainda, avaliar os mapas, as imagens, a bibliografia, os documentos e as atividades propostas no livro, bem como as sugestões ao professor - se disponíveis -, além de detectar simplificações, generalizações e erros de conteúdo.

No quinto item, o grupo deveria, de forma sintética, apresentar a avaliação do MEC quanto ao livro. Em alguns casos este item não pôde ser realizado, pois muitos dos livros selecionados para análise não foram previamente avaliados. ${ }^{15}$

No sexto, foi solicitada a comparação dos conteúdos presentes no livro didático com o dos textos acadêmicos lidos e discutidos durante a disciplina. Aqui o objetivo era duplo: que os alunos identificassem as diferenças entre os textos acadêmicos e os didáticos e que pudessem recordar e aprofundar as reflexões sobre os conteúdos que foram ministrados no decorrer do semestre letivo.

A comparação do conteúdo presente no livro didático com os PCNs relacionados ao ciclo/série correspondente foi a meta do item sete. O objetivo aqui era estimular a leitura dos PCNs e verificar a unidade entre os parâmetros para o ensino de história medieval e os conteúdos dos livros.

$\mathrm{O}$ item oito exigia um posicionamento do grupo em relação ao uso dos livros didáticos para o ensino de História no ensino fundamental e médio, apontando as vantagens e as desvantagens. Por fim, como último item, pediu-se que o grupo propusesse uma atividade didática com o uso do livro analisado. Também foi solicitada a inclusão da bibliografia consultada para a elaboração do trabalho e uma fotocópia dos capítulos analisados.

Foram entregues 12 trabalhos. Todos foram realizados em grupo. Eles diferiram muito quanto ao tratamento dado aos itens. Alguns tinham duas laudas, e outros, mais de vinte. Muitos optaram por não seguir o roteiro, mas elaborar um texto em que os itens fossem contemplados; contudo, em alguns casos, um ou mais itens foram suprimidos.

Em alguns trabalhos ficou nítido que nem todos os grupos compreenderem o que foi solicitado. Por exemplo, ao invés de proporem atividades didáticas com o uso do livro, só criticaram os exercícios do livro analisado. Também ficou evidente a dificuldade de desenvolver o solicitado em alguns itens, como a identificação dos pressupostos pedagógicos que fundamentam a obra ou a separação da avaliação do MEC da do próprio grupo sobre o material. 
A fim de obter um feedback da turma em relação à introdução do tema ensino de história medieval e às atividades propostas, na aula anterior à entrega dos trabalhos e prova final, foi solicitado aos alunos que respondessem a um questionário, que também segue ao final do artigo, sem a necessidade de se identificar. Também foram propostas perguntas sobre as experiências pessoais dos alunos com a aprendizagem da História medieval.

O questionário, com 14 questões fechadas, sem dúvida pôde induzir a algumas respostas. Além disso, ainda que não tenham se identificado, é possível que um ou outro aluno tenha respondido às perguntas preocupado com a nota a ser obtida no trabalho. Nesse sentido, longe de considerar que o resultado do questionário, que passo a apresentar a seguir, representa uma avaliação isenta e fiel da turma sobre o tema, prefiro ponderar que se trata de uma perspectiva aproximada.

Dos 41 alunos que cursaram a disciplina, 33 responderam ao questionário. Vale destacar que destes, 5 cursavam, então, o terceiro período do bacharelado; 11, o quarto; 3, o quinto; 4, o sexto; 3 , o sétimo; 3 , o oitavo; 3 , o nono, e 1 o décimo. Os questionários foram entregues aos alunos, que leram, interpretaram e responderam às perguntas de forma privada. Ou seja, não foi feita nenhuma leitura ou explanação do que se buscava obter com as respostas, salvo a informação impressa no texto, e que foi repetida oralmente por mim, de que as respostas seriam usadas na redação deste artigo.

Do conjunto de 33, 29 declararam que no ensino fundamental e/ou médio estudaram conteúdos referentes ao medievo, enquanto quatro marcaram “não". Como as escolas adotam livros e currículos diferentes, é possível, de fato, que alguns alunos que mudaram de escola possam não ter tido a chamada História Geral, que em algumas é ministrado nos $8^{\circ}$ e $9^{\circ}$ anos e, em outras, nos $6^{\circ}$ e $7^{\circ}$. Além disso, os conteúdos referentes ao medievo muitas vezes compõem a última unidade a ser abordada e, devido à falta de tempo, não são nem apresentados aos alunos. Por fim, também é provável que alguns até tenham tido contato com a história do período medieval, mas não se recordam.

Quando questionados a comparar os conteúdos sobre a história medieval aprendidos no ensino fundamental e médio com os que foram apresentados nesta disciplina, 19 consideraram como totalmente diferentes, 9 como similares, 1 como iguais e 3, que responderam “não" na pergunta anterior, também 
marcaram "Totalmente diferentes", o que pode indicar uma falta de atenção ou de compreensão das questões ao responderem ao questionário.

Essa resposta aponta para o persistente abismo entre o que é discutido nos ambientes acadêmicos e o que é ensinado nas escolas. Os conteúdos difundidos na escola, em muitos casos, pautam-se em perspectivas historiográficas que já foram revistas em pesquisas mais recentes ou, mesmo quando incorporam as novas interpretações, estas são apresentadas de forma simplificada ou esquemática.

A pergunta seguinte teve como objetivo conhecer o interesse historiográfico sobre o período medieval dos graduandos que cursaram a disciplina, visto que se trata de uma disciplina obrigatória. Enquanto 1 aluno não marcou nenhuma das opções, 11 informaram ter muito interesse, outros 18 se declararam indiferentes e 3 disseram que não têm o menor interesse. Este dado também é digno de reflexão: a despeito da persistente visão estereotipada sobre o medievo, um terço dos alunos que responderam ao questionário têm muito interesse sobre a história do período. É provável que tal interesse não se deva unicamente aos conteúdos apresentados no ensino fundamental e médio, mas às visões sobre a Idade Média recriadas e difundidas pelos mass media, como o cinema, a literatura e os jogos eletrônicos.

A questão seguinte buscava identificar, dentre os que responderam ao questionário, quais alunos já lecionam ou pretendem lecionar no ensino fundamental, médio ou em cursos preparatórios. A maioria, 23, informou que sim, enquanto 10 responderam que não.

Com o objetivo de verificar como os alunos veem a relação entre a prática docente, as reflexões pedagógicas, o domínio dos conteúdos específicos e as técnicas de ensino, 29 responderam que é necessário, para lecionar no nível fundamental, médio ou em cursos preparatórios, dominar os conteúdos sobre a matéria a ser lecionada e as técnicas de ensino, bem como ter reflexões pedagógicas. Para 2 alunos os conteúdos são mais importantes do que as reflexões pedagógicas e o conhecimento das técnicas de ensino, e para outros 2 é o contrário: é mais importante ter reflexões pedagógicas e dominar técnicas de ensino do que os conteúdos sobre a matéria a ser ministrada.

Creio que estas respostas são extremamente relevantes, já que revelam a sensibilidade de grande parte dos alunos, mesmo que de diferentes períodos, 
em perceber a necessidade de unir saberes para aplicá-los ao ensino, sem criar uma hierarquia entre eles.

A pergunta a seguir indagava se o aluno considerou relevante para a sua formação acadêmica a inclusão de uma unidade sobre ensino de História Medieval na disciplina em tela. Do conjunto, 28 responderam que sim e 5 que não. Foram listados cinco motivos para justificar a resposta positiva, e foi informado que mais de um item poderia ser assinalado. Aqui também havia a opção de marcar o item "Outro" e incluir uma resposta pessoal.

Dentre os itens que já figuravam no questionário, dos 28, 16 assinalaram que consideraram a inclusão positiva porque pretendem atuar como professores; 5 porque conhecem pessoas em idade escolar e têm interesse em saber como o período medieval é apresentado aos alunos; 7 devido às políticas públicas relacionadas ao tema, e 11 para ter acesso às discussões acadêmicas sobre a temática. Dentre as respostas livres, 1 indicou que era uma forma de melhor conhecer o período medieval, 2 registraram que era importante para obter mais conhecimentos em geral, e 1, devido ao caráter de pesquisa na abordagem da questão.

Para os que responderam de forma negativa, 1 justificou sua resposta indicando que o tema é "muito chato", 3 que esta temática deve ser tratada só nas aulas de didática, 3 porque, ao introduzir esse tema, tiveram acesso a um número menor de conteúdos sobre o período medieval. Dentre as opções listadas no questionário, mas que não foi marcada por ninguém, encontrava-se "o curso é de bacharelado e este tema não está relacionado à formação do historiador". Alguns elaboraram respostas individuais, mas que eram similares às listadas no questionário. Portanto, foram contabilizadas entre estas.

Aqui, mais uma vez, fica evidenciado que só uma parcela pequena dos que responderam ao questionário não consegue perceber que as temáticas relacionadas ao ensino de História Medieval são relevantes para serem pensadas em um curso que trata dos conteúdos historiográficos sobre esse período histórico. Talvez porque não considerem que as visões disseminadas sobre o medievo no ensino fundamental e médio também são conhecimentos sobre o passado que possuem relação direta com a historiografia que é produzida, ainda que com algum descompasso, na academia.

As perguntas 10 e 11 tinham como objetivo verificar se os alunos já possuíam conhecimentos sobre os PCNs, o PNLD e PNLEM. Dos 33, 24 
afirmaram que não leram antes da disciplina os documentos sobre a distribuição de livros didáticos pelo MEC e 23, sobre os PCNs.

As últimas perguntas se relacionam de forma específica ao trabalho final em grupo sobre o livro didático. Somente 1 aluno considerou muito difícil, e 9 classificaram o exercício como difícil. A maioria, 22, respondeu que era “Trabalhoso, mas não difícil”. Ninguém marcou as opções "Fácil” e "Muito fácil”, e 1 não respondeu à pergunta.

Também foi perguntado que itens do roteiro proposto para a realização do trabalho o aluno considerava desnecessários ou fundamentais para conhecer o livro didático em análise. Aqui houve uma resposta unanime: os 33 que responderam ao questionário consideraram fundamental a análise do conteúdo do livro. Os demais itens e as respectivas respostas figuram nesta tabela:

\begin{tabular}{l|c|c}
\hline \multicolumn{1}{c|}{ Item } & Desnecessário & Fundamental \\
\hline Identificação da obra & 2 & 31 \\
Autoria & 3 & 30 \\
Aspectos formais do livro & 18 & 15 \\
Avaliação do MEC & 14 & 19 \\
Relação com a produção acadêmica & 3 & 30 \\
Relação com os PCNs & 12 & 21 \\
Avaliação do livro pelo grupo & 6 & 27 \\
Proposição de atividades ${ }^{16}$ & 9 & 22 \\
\hline
\end{tabular}

Nestas respostas, dois aspectos me chamaram bastante a atenção. Em primeiro lugar, o pouco valor dado aos aspectos formais do livro, como se estes tivessem menor importância e não interferissem no acesso e compreensão do conteúdo. Em segundo, ainda que não tenham sido itens escolhidos pela maioria, a relação entre livros didáticos e políticas e normativas públicas não foi considerada fundamental por cerca de um terço dos alunos, o que aponta para uma perspectiva que não vê o ensino e a produção dos livros didáticos de forma crítica, politizada e relacionada às diretrizes governamentais.

A última questão indagou se a realização do trabalho auxiliou na mudança da visão sobre o livro didático de História Medieval. A resposta apresentada aqui mostrou a coerência dos que responderam ao questionário, pois assim 
como 28 alunos consideraram relevante para a sua formação acadêmica a inclusão de uma unidade sobre ensino de história medieval, 28 também declararam que sua perspectiva sobre o livro didático sofreu transformações. Destes, 14 assinalaram que a intensidade dessa transformação foi grande; 8 , regular; 4, pouca, e 2 deixaram em branco.

Após analisar o questionário, mesmo tomando as respostas como uma visão aproximada dos alunos sobre o tema tratado, como já assinalado, avalio como positiva a inclusão da unidade sobre ensino de história medieval na disciplina ministrada. Não só porque a maioria dos alunos a considerou relevante, mas porque a introdução desse tópico me obrigou a repensar as relações que estabeleço entre ensino e pesquisa no âmbito da própria disciplina ministrada e me estimula a problematizar a questão e instituir novas práticas.

Como docente de História Medieval, identifico ainda muitos tópicos relacionados ao ensino desta disciplina que necessitam ser discutidos com profundidade: como equilibrar a transmissão dos conteúdos sobre o período medieval, que resultam das reflexões historiográficas, com o estímulo para que os alunos sejam críticos em relação a estes próprios saberes? Como articular a apresentação dos conteúdos com as reflexões teóricas que os fundamentam? Como motivar o estudo sobre temas particulares sem renunciar à reflexão sobre as análises de conjunto? Como propor análises mais globais, sem cair na esquematização? Como motivar os alunos a produzirem novos conhecimentos no desenrolar da disciplina? Como criticar os livros didáticos sem desenvolver uma visão negativa sobre o que é ministrado no ensino fundamental e médio? Como articular os saberes historiográficos lidos e discutidos durante o curso, de matriz predominante europeia, com as metas dos PCNs, que valorizam o estudo dos povos e culturas africanos e indígenas para a formação da sociedade brasileira, dando menor espaço para as contribuições dos europeus?

As dicotomias ainda imperam no meio acadêmico brasileiro, criando hierarquias e abismos entre o ensino superior e o ensino fundamental e médio; entre as atividades de pesquisa e de ensino; entre o domínio de conteúdo e a habilidade pedagógica etc. Por outro lado, as atividades de ensino e pesquisa são naturalizadas, consideradas neutras e balizadas pela razão. Tais atividades, entretanto, como outros fenômenos sociais, resultam, dentre outros fatores, de relações de poder e de escolhas institucionais. Cotidianamente reafirmamos 
as dicotomias e hierarquias entre elas, pois não desconstruímos essas perspectivas com reflexões críticas e novas práticas.

Nesse sentido, acredito que a experiência aqui relatada, que será retomada e revista numa constante (re)construção, possa estimular outros professores a buscarem formas de aproximar a prática docente em diferentes níveis escolares à reflexão acadêmica, a fim de formarmos profissionais mais completos, que se recusem a repetir as antigas dicotomias hierárquicas e que possam produzir conhecimentos históricos múltiplos, atentos às preocupações teóricas e conceituais, às diferentes correntes historiográficas e à transmissão de saberes.

\section{REFERÊNCIAS}

BUSTAMANTE, R. M. da C. (Org.) Manual do estudante. Rio de Janeiro: Instituto de História, 2011.

FRANCO JR., H. A Idade Média. O Nascimento do Ocidente. 2.ed. São Paulo: Brasiliense, 2001.

MACEDO, J. R. Introdução - Cinema e Idade Média: perspectivas de abordagem. In: .; MONGELLI, L. M. (Org.) A Idade Média no cinema. São Paulo: Ateliê Editorial, 2009. p.13-47.

PAULA, M. F. A produção do conhecimento e seus locais de difusão: uma reflexão sobre o abismo. In: SILVA, A. C. L. F. da; SILVA, L. R. da (Org.) SEMANA DE ESTUDOS MEDIEVAIS, 7., 2007, Rio de Janeiro. Atas... Rio de Janeiro: Programa de Estudos Medievais, 2008. p.109-115.

PEREIRA, N. M. Imagens da Idade Média na Cultura Escolar. In: ALMEIDA, C. C.; PEREIRA, N. M.; TEIXEIRA, I. S. (Org.) Reflexões sobre o medievo. Porto Alegre: Oikps-Anpuhrs, 2009. p.23-38. 


\section{ANEXO}

\section{Ficha de Análise do Livro Didático}

\section{Livro Analisado:}

Título

Editora

Série a que se destina

Ano de publicação

Edição

Informações sobre a coleção da qual faz parte, destacando o tipo de coleção (temática, integrada, intercalada ou convencional)

\section{Autoria:}

Nome do(s) autor(es)

Formação acadêmica

Vinculação institucional

Outras obras produzidas

\section{Observações quanto à forma:}

a. Tamanho

b. Número de páginas

c. Nitidez das letras impressas

d. Disposição gráfica (descrição e avaliação)

e. Papel (espessura e cor)

f. Capa (qualidade e estética)

g. Qualidade da encadernação

h. Durabilidade

i. Facilidade de manuseio e transporte levando em conta a idade do grupo a que se destina

j. Preço

\section{Observações quanto ao conteúdo:}

a. Temas tratados

b. Organização e estruturação do Conteúdo 
c. Pressupostos pedagógicos

d. Conceitos teóricos empregados

e. Obras historiográficas citadas

f. Vocabulário e informações adequadas à idade/série a que se destina

g. Validade e profundidade das informações contidas no livro

h. Presença de preconceitos

i. Avaliação dos mapas, imagens, bibliografia e documentos apresentados no texto

j. Avaliação das atividades propostas

k. Avaliação das Sugestões ao professor

1. Presença de erros de conteúdo

\section{Avaliação do MEC quanto ao livro}

VI. Comparação do conteúdo presente no livro didático com o dos textos acadêmicos

VII. Comparação do conteúdo presente no livro didático com os PCNs relacionados ao ciclo/série correspondente

VIII. Avaliação do grupo quanto às vantagens e desvantagens do uso do livro para o ensino de História no ensino fundamental e médio

IX. Proposição de atividades didáticas com o uso do livro didático analisado

X. Bibliografia consultada

\section{Questionário}

1. Você é aluno de qual período?

2. No ensino fundamental e/ou médio você estudou conteúdos referentes ao medievo?
( ) $\operatorname{Sim}$
( ) Não 
3. Face ao aprendido anteriormente, os conteúdos que lhe foram apresentados nesta disciplina são:

( ) Totalmente diferentes ( ) Similares ( ) Iguais

4. Como você classifica seu interesse historiográfico sobre o período medieval:

( ) Muito grande ( ) Indiferente ( ) Não tenho o menor interesse

5. Você já leciona ou pretende lecionar no ensino fundamental, médio ou em cursos preparatórios?

( ) Sim ( ) Não

6. Para lecionar no nível fundamental, médio ou em cursos preparatórios, em sua opinião:

( ) é mais importante ter conteúdos sobre a matéria a ser lecionada do que ter reflexões pedagógicas e dominar técnicas de ensino.

( ) é mais importante ter reflexões pedagógicas e dominar técnicas de ensino do que dominar os conteúdos sobre a matéria a ser lecionada.

( ) é necessário dominar os conteúdos sobre a matéria a ser lecionada e reflexões pedagógicas, bem como dominar técnicas de ensino.

7. Você considerou relevante para a sua formação acadêmica a inclusão de uma unidade sobre ensino de História medieval nesta disciplina?

( ) $\operatorname{Sim}($ ) Não

8. Em caso positivo, por quê? Pode marcar mais de um item.

( ) pretendo ser professor.

( ) tenho pessoas próximas em idade escolar e tenho interesse em saber como o período medieval é apresentado aos alunos.

( ) devido às políticas públicas relacionadas ao tema.

( ) para ter acesso às discussões acadêmicas sobre o tema.

( ) outro. Indique:

9. Em caso negativo, por quê? Pode marcar mais de um item.

( ) curso o bacharelado e este tema não está relacionado à formação do historiador.

( ) é um tema muito chato. 
( ) este tema deve ser tratado só nas aulas de didática.

( ) ao introduzir este tema, temos acesso a um número menor de conteúdos sobre o período medieval.

( ) outro. Indique:

10. Antes desta disciplina você já tinha lido sobre o PNLD ou PNLEM?

( ) Sim ( ) Não

11. E sobre os PCNs?

( ) Sim ( ) Não

12. Como você classifica o grau de dificuldade do trabalho final em grupo sobre o livro didático:

( ) Muito difícil ( ) Difícil ( ) Trabalhoso, mas não difícil

( ) Fácil ( ) Muito fácil

13. Que itens abaixo você considera desnecessários ou fundamentais para conhecer um livro didático:

- identificação da obra:

( ) Desnecessário （）Fundamental

- autoria:

( ) Desnecessário ( ) Fundamental

- aspectos formais do livro:

( ) Desnecessário （ ) Fundamental

- análise do conteúdo:

( ) Desnecessário ( ) Fundamental

- avaliação do MEC:

( ) Desnecessário ( ) Fundamental

- relação com a produção

acadêmica:

( ) Desnecessário ( ) Fundamental

- relação com os PCNs:

( ) Desnecessário ( ) Fundamental

- avaliação do livro pelo grupo: （）Desnecessário （）Fundamental

-proposição de atividades: （ ）Desnecessário （ ）Fundamental 
14. A realização do trabalho auxiliou na mudança de sua visão sobre o livro didático de História Medieval?

( ) Sim ( ) Não. Em que intensidade? （ ） Muito
( ) Regularmente ( ) Pouco

\section{NOTAS}

${ }^{1}$ Professora do Instituto de História da UFRJ. Pesquisadora do CNPq. Co-coordenadora do Programa de Estudos Medievais da UFRJ. Mestre em História Antiga e Medieval UFRJ e Doutora em História Social - UFRJ. Este artigo é dedicado aos alunos de Graduação em História da UFRJ que cursaram a disciplina História Medieval II no turno noturno no primeiro semestre letivo de 2011.

${ }^{2}$ As reflexões aqui apresentadas vinculam-se ao projeto Reflexões Sobre o Ensino de História Medieval, a Produção de Materiais e Estratégias Didáticas para o Uso em Sala de Aula, coordenado por mim e pela profa. dra. Leila Rodrigues da Silva, vinculado ao Programa Pró-docência - UFRJ (2011-2012), financiado pela Capes. Mais informações: www. im.ufrj.br/licenciatura/pag/pag/Pagina_Prodocencia/index.html.

${ }^{3}$ Outras cronologias têm sido propostas para o período, como a presente no manual de Hilário Franco Jr., Idade Média. O nascimento do Ocidente, que propõe a divisão do período em quatro momentos: Primeira Idade Média (princípios do século IV a meados do século VIII), Alta Idade Média (meados do século VIII-fins do X), Idade Média Central (séculos XI-XIII) e Baixa Idade Média (século XIV-meados do século XVI) (Cf. FRANCO JR., 2001, p.15-17).

${ }^{4}$ Vale destacar que são previstos dez períodos para que o aluno do turno noturno do bacharelado e da Licenciatura em História conclua sua graduação. Cf. BUSTAMANTE, 2011, p.13.

${ }^{5}$ Em todos os semestres, as disciplinas História Medieval I e II são oferecidas nos dois turnos do Curso de Graduação em História da UFRJ.

${ }^{6}$ Empregamos, aqui, o conceito de medievalidade proposto por Rivair Macedo: "Neste último caso, diferentemente das 'reminiscências', que de alguma forma preservam algo da realidade histórica da Europa medieval, defrontamo-nos com uma das manifestações mais tangíveis da 'medievalidade', em que a Idade Média aparece apenas como uma referência, e por vezes uma referência fugidia, estereotipada. Assim, certos índices de historicidade estarão presentes em manifestações lúdicas, obras artísticas ou técnicas de recriação histórica (na reconstituição erudita do canto gregoriano ou das cantigas dos trovadores ou nas atividades de recriação histórica de torneios, feiras, festas, cutelaria ou culinária 'medieval'), mas a Idade Média poderá vir a ser uma realidade muito mais imprecisa na inspiração de temas (magos, feiticeiros, dragões, monstros, guerreiros, assaltos a fortalezas) produzidos pelos meios de comunicação de massa e pela indústria cultural" (Cf. MACEDO, 2009, p.16-17). 
${ }^{7}$ Compreendemos aqui, como saber escolar, aquele que é transmitido nas escolas de ensino fundamental e médio.

${ }^{8}$ Não ministrei a disciplina História Medieval II no ano letivo de 2012.

9 Todos os documentos referentes aos PCN podem ser acessados em: http://portal.mec. gov.br.

${ }^{10}$ O PCNEM para a área de Ciências Humanas está disponível em: http://portal.mec.gov. br/seb/arquivos/pdf/book_volume_03_internet.pdf.

${ }^{11}$ Os guias do PNLD, de 1997 a 2008, estão disponíveis no Portal do MEC.

${ }^{12}$ Sobre o PNLEM, ver: http://portal.mec.gov.br/index.php?id=13608\&option=com_ content\&view=article.

${ }^{13}$ Após a unidade sobre Ensino de História, ainda foram desenvolvidas outras sete em cerca de 3 meses.

${ }^{14}$ Segundo o Guia do PNLD de 2008, uma coleção temática é aquela que estrutura o conteúdo por temas; uma coleção de história Integrada “oferece concomitantemente a História do Brasil, a da América e a da História Geral, podendo seguir ou não a ordem cronológica do estabelecimento das sociedades"; a "História Intercalada ordena a História do Brasil e da América junto com a História Geral, normalmente em ordem cronológica crescente, mas os conteúdos não são relacionados entre essas histórias; apenas os assuntos são alternados nos espaços em que ocorreram"; e por fim, as Coleções convencionais que abordam a História do Brasil no sexto e sétimo anos e a chamada História Geral no oitavo e nono (MEC, 2007, p.11-12). Em relação ao PNLEM, não há um Guia disponível on-line, mas uma portaria que divulga o resultado das avaliações dos livros. No que concerne às áreas curriculares de História e Geografia referentes ao PNLEM/2007, ver: http://portal. mec.gov.br/seb/arquivos/pdf/port907_pnlem.pdf; Acesso em: 15 jul. 2011.

${ }^{15}$ Vale destacar que o MEC não avalia todos os materiais didáticos e paradidáticos produzidos no país, só os que são inscritos pelas editoras para comporem o PNLD ou PNLEM.

${ }^{16}$ Este item foi deixado em branco em dois questionários.

Artigo recebido em setembro de 2013. Aprovado em outubro de 2013. 